\title{
Abrasion rates of ventifacts
}

\author{
Wen-Xiao $\mathrm{Ning}^{1} \cdot$ Xiao-Qi Huang ${ }^{2} \cdot$ Xue-Song Wang $^{2} \cdot$ Qing $^{\mathrm{Li}^{3}} \cdot$ Zhen-Ting Wang $^{1}$ (I)
}

(c) Springer Nature Switzerland AG 2019

\begin{abstract}
Although ventifacts are often utilized to determine past and present wind directions and sediment mobilities in arid, coastal, and periglacial environments, their morphodynamics have not been well understood. In this study, based upon the principles of classical mechanics, the abrasion rate of ventifact is analytically expressed by the elastic properties of rock or mineral components and the mass flux density of sediment transported by wind. The unknown abrasion coefficient can be estimated via wind tunnel experiments. The practicability of this novel formula is shown by the calculation of short-term abrasion depth of ventifacts over a desert pavement. It is expected that the current work will improve the quantitative reconstruction of paleo-environments and paleo-climates using ventifacts.
\end{abstract}

Keywords Ventifact $\cdot$ Abrasion rate formula $\cdot$ Aeolian sediment transport

\section{Introduction}

Ventifacts are pebble- to boulder-sized rocks shaped by aeolian particles in arid, coastal, and periglacial environments [1-3]. Stone pavements cover more than $50 \%$ of terrestrial desert surfaces [4]. The ventifacts in the northern hemisphere midlatitudes are particularly reported in the literature [1]. Ventifacts are also widespread on Mars [5, 6], because of highly active aeolian sediment transport and abrasion processes. As a typical type of erosional landform as well as yardangs, they are significant in determining past and present wind direction and sediment mobility $[1,2]$. Both morphological and morphodynamic studies on this landform have been performed frequently since 1855 , in which two papers closely related with ventifacts were published [7]. Depending on wind conditions, small ventifacts might have one or more facets separated by sharp keels. There are Brazil-nut, pyramidal, and other shapes in plan view, and some distinctive surface features such as pits, flutes and grooves, see $[3,8,9]$ for more detailed morphological characteristics. Ventifact formation is influenced by factors similar to those of dunes [10]. Morphodynamic processes, abrasion in particular, can be investigated by means of field investigation $[8,11-14]$, numerical simulation $[15,16]$, laboratory simulation [17-25], and theoretical analysis $[26,27]$. Field investigations are commonly time-consuming. A long-term field observation suggested that the abrasion of the ventifacts located at a small western Arctic coastal settlement had been virtually undetectable over 50 years [14]. As a comparison, the formation and development of facets and surface features by direct impacts of sand grains can be numerically modeled efficiently $[15,16]$. But the principles of these numerical simulations are weakly supported by physical laws. As far as we know, more practical methods are abrasion experiments using the apparatuses specially designed [19-21] or various kinds of wind tunnels [17, 18, 24, 25]. Abrasion rate must be determined firstly, in order to quantificationally describe the morphodynamic processes of ventifacts. This variable is a function of wind velocity, particle supply,

$\triangle$ Zhen-Ting Wang, wangzht@lzu.edu.cn | ${ }^{1}$ Northwest Institute of Eco-Environment and Resources, CAS, Lanzhou 730000, People's Republic of China. ${ }^{2}$ State Key Laboratory of Earth Surface Processes and Resource Ecology, MOE Engineering Research Center of Desertification and Blown-sand Control, Beijing Normal University, Beijing 100875, People's Republic of China. ${ }^{3} \mathrm{Hebei}$ Engineering Research Center for Geographic Information Application, Institute of Geographical Sciences, Heibei Academy Sciences, Shijiazhuang 050011, People's Republic of China. 
and the mechanical properties of rocks etc. For an impact, it is traditionally recognized that the mass lost is roughly proportional to the translational energy of the impacting particle $[18,20,21,26]$. This empirical "abrasion law" can be reasonably expanded to include two common mechanical parameters of target materials by modeling the collision and break precesses [27]. Recently, A unified equation of the rate of bedrock erosion by sediment-laden fluid flows in fluvial, coastal, and aeolian environments was put forward [28], although the theoretical foundation is lacking. In the presented study, a mechanically-based novel expression of abrasion rate is derived according to the principles of classical mechanics and the abrasion model proposed by Wang et al. [27], and then field observation is performed to test the formula.

\section{Methodology}

\subsection{Theoretical model}

The volume of target material removed by an impact can be written as [27],

$\frac{V}{d^{3}} \propto \frac{\rho_{s} u^{2} E}{\sigma_{s}^{2}}$

where $V$ is the volume lost, $\rho_{s}, d$, and $u$ are the density, diameter, and speed of the impacting particle, $E$ and $\sigma_{s}$ are Young's modulus and yield stress of the target, respectively.

Abrasion rate is often defined as the eroded depth of target materials per unit time. A basic fact is that the failure area of brittle materials generally increases with the increase of the size of impacting rigid grains. Therefore, the volume lost $V$ per impact is,

$V \propto h d^{2}$

where $h$ is the eroded depth.

Given the mass flux density $q$, defined as the mass perpendicularly passing through an unit area per unit time, the mass transported by wind through an area of a grain in duration $T$ is

$\delta m=\frac{1}{4} q \pi d^{2} T=\frac{1}{6} n \rho_{s} \pi d^{3}$

where the sand grain is assumed to be a perfect sphere, $n$ is the grain number.

Hence, the impact times is,

$n=\frac{3 q T}{2 \rho_{s} d}$
The length of "sand column" through the area of a grain is,

$I=\frac{\frac{1}{6} n \pi d^{3}}{\frac{1}{4} c \pi d^{2}}=\frac{2 n d}{3 c}$

where $c$ is the volume concentration of aeolian sand.

From Eqs. (4) and (5), the speed of a single impacting grain is,

$u=\frac{l}{T}=\frac{q}{c \rho_{s}}$

Combining Eqs. (1), (2), (4), and (6), the expression of abrasion rate is derived as,

$v_{a}=\frac{n h}{T}=C_{a} \frac{q^{3} E}{\rho_{s}^{2} \sigma_{s}^{2}}$

where the empirical constant $C_{a}$ can be named as "abrasion coefficient". The volume concentration $c$ was assumed to be a constant, and has been contained in $C_{a}$. Hereinafter, the function form in the right side of (7) and the unknown abrasion coefficient $C_{a}$ will be verified and determined by the previous experimental data.

\subsection{Field observation}

Given a ventifact, $E$ and $\sigma_{s}$ in (7) can be found from large numbers of materials handbooks, e.g. [29]. Table 1 lists these two mechanical parameters we adopted in this study. For a saturated aeolian transport, many mass flux expressions or numerical simulation procedures have been developed [30]. However, the granular material supply for wind-blown sediments shaping ventifacts is often limited in a natural environment. To determine the unsaturated mass flux density $q$ and examine the practicability of the theoretical expression (7), we designed and performed a field observation over a

Table 1 Mechanical parameters of common rock or mineral components of ventifacts (No. 1-5) and the material used in the simulation experiments (No. 6)

\begin{tabular}{lllr}
\hline No. & Rock/Mineral & $E(\mathrm{GPa})$ & $\sigma_{\mathrm{s}}(\mathrm{MPa})$ \\
\hline 1 & Basalt & 72.0 & 343.0 \\
2 & Granite & 54.0 & 204.0 \\
3 & Marble & 48.5 & 145.0 \\
4 & Quartzite & 67.5 & 288.8 \\
5 & Fused silica & 72.0 & 1100.0 \\
6 & Sandstone (soft) & 0.98 & 10.0 \\
\hline$E$ and $\sigma_{s}$ are Young's modulus and yield stress (compressive \\
Strength), respectively
\end{tabular}

SN Applied Sciences 
desert pavement at the Dashagou gobi of the Kumtagh desert (China) in the spring of 2017. In this region, the prevailing wind direction is northwest $\left(295^{\circ}\right)$. The gravel cover and vegetation cover of the desert pavement are about $20-40 \%$ and $5-15 \%$, respectively. The wind velocities at the heights of $0.5 \mathrm{~m}$ and $1.0 \mathrm{~m}$ above the surface were automatically and continuously recorded by two super sonic anemometers (Fig. 1a) with the sampling frequency of $20 \mathrm{~Hz}$ during March 22 to May 2. The near-surface mass flux was artificially and discontinuously measured by using a conventional sand collector (Fig. 1b) with the sampling efficiency larger than $90 \%$. The mean grain size of aeolian sediment is about $200 \mu \mathrm{m}$. Meanwhile 15 soft sandstone blocks with the dimension of $20 \mathrm{~cm} \times 10 \mathrm{~cm} \times 10 \mathrm{~cm}$ or so were cut and smoothed from natural alluvial deposits, and then were placed at this ventifact site to observe the perceptible effects of abrasion by aeolian sand grains. Both the inlet of the sand collector and the front faces of sandstone blocks were perpendicular to the prevailing wind direction.

The natural process of aeolian sediment transport is highly intermittent [31-33]. Friction speed and duration are two dominating factors. Wind erosion events can be detected from the time series of wind speed in the prevailing wind direction. Here the minimal durations of erosion and non-erosion events are empirically set to be $0.5 \mathrm{~min}$ and $0.25 \mathrm{~min}$. The friction speed $u_{*}$ in a wind erosion event must be larger than the threshold friction speed $u_{* t}(\approx 0.30 \mathrm{~m} / \mathrm{s})$. In the numerical program of data analysis, erosion and non-erosion events are not allowed to contain each other. The sediments transported by several to hundreds of wind erosion events were collected in one sampling time $(10-60 \mathrm{~min})$ of the sand collector. If the number of wind erosion events in one run for collecting aeolian sand, the friction speed and duration of the i-th event are denoted as $N, u_{* i}, t_{i}$, then the time-averaged friction speed $u_{*}$ can be calculated by $\sum_{i=1}^{N} u_{* i} t_{i} / \sum_{i=1}^{N} t_{i}$.

\section{Results and discussion}

\subsection{Function form}

The abrasion law of (1) has been confirmed by the experimental data of [20, 22], see Fig. 7 in Ref. [27] for details. As a conclusion, the expression of abrasion rate (7) should be valid. Unfortunately, all variables and parameters in (7) are seldom measured simultaneously in existing abrasion experiments. We only found one experiment in which the strengths of rock specimens were tested [19]. Figure 2 shows that the relation between abrasion rate and the compression strength of sandstone can be well fitted by $v_{a} \propto \sigma_{s}^{-2}$ when sand flux is constant. This reconfirms that the function form of (7) is acceptable.

\subsection{Abrasion coefficient}

The empirical constant $C_{a}$ in (7) can be estimated, according to the wind tunnel experiments conducted

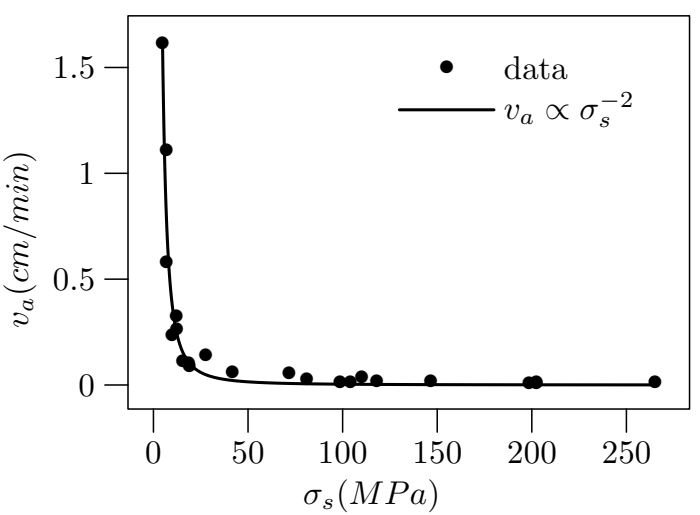

Fig. 2 The relation between abrasion rate and compression strength for sandstone can be well fitted by $v_{a} \propto \sigma_{s}^{-2}$ when sand flux keeps constant. This reconfirms that the function structure of (7) is acceptable. The experimental data denoted by "•" are sourced from Ref. [19]
Fig. 1 Two super sonic anemometers and one sand collector were utilized to measure wind velocity and mass flux density over a desert pavement. The super sonic anemometers were located at the height of $0.5 \mathrm{~m}$ and $1.0 \mathrm{~m}$ above the surface. The sand collector is $60 \mathrm{~cm}$ high

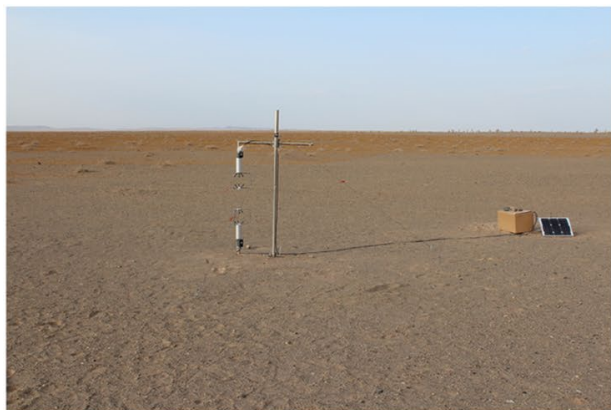

(a) Two super sonic anemometers.

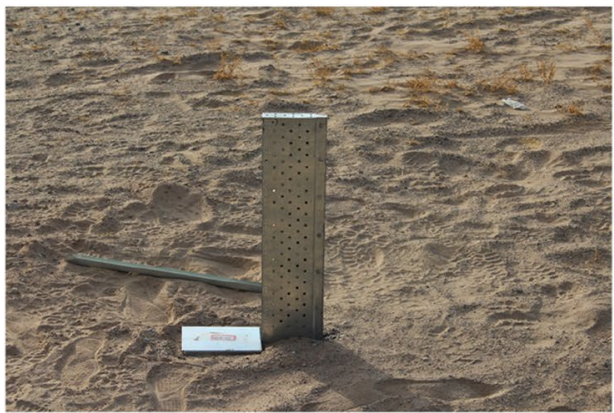

(b) One sand collector. 
by Bridges et al [24]. Most extant ventifacts are igneous or metamorphic [34]. Since the short-term, e.g. quarterly or annual, abrasion rates of nature rocks and mineral of ventifacts, such as basalt, chert, and quartz, are too small or unnoticeable, the materials with much lower strength are widely served as targets in abrasion experiments. The material of soft sandstone was successfully simulated by a mosaic of water, gypsum and sand in their wind tunnel experiments [24]. The sandstone simulant target with flat sides and the front face angled at different degrees relative to the tunnel floor was abraded by sand flux in the wind tunnel. The target losses mass and forms the ventifact-like surface features during this abrasion process. The change of target weight was recorded in each experiment run. Totally, nine abrasion rates for the front face of three targets perpendicular to the wind direction were obtained under the condition of a constant sand flux of $0.4 \mathrm{~kg} / \mathrm{min}$. Aeolian sediment transport mainly occurs in the near-bed flow region. An optical measurement in a wind tunnel with the cross-section of $0.3 \mathrm{~m} \times 0.3$ $\mathrm{m}$ indicates that the region above $19 \mathrm{~mm}$ from the bed generally makes only $20 \%$ contribution to total mass flux [35]. Note that the dimensions of the wind tunnel are larger and the wind speed is higher in the experiments of Bridges et al [24], we assume that the mass flux contribution in the region of abrasion targets is $50 \%$. Consequently, the mass flux density $q$ is computed to be $0.056 \mathrm{~kg} / \mathrm{m}^{2}$. The typical values of Young's modulus $E$ and yield stress $\sigma_{s}$ of soft sandstone are listed in Table 1. Substituting $q, E, \sigma_{s^{\prime}} \rho_{s}\left(\approx 2.65 \times 10^{3} \mathrm{~kg} / \mathrm{m}^{3}\right)$, and the measured $v_{a}$ into (7), it is found that the abrasion coefficient $C_{a}$ ranges from $1.79 \times 10^{8}$ to $5.36 \times 10^{9}$, and the mean value is $3.00 \times 10^{9}$.

\subsection{Morphological change}

Although ventifact-like shapes did not develop owing to the relative short observation period, the windward surface of sandstone block was morphologically changed by the abrasion of aeolian sand grains. As shown in Fig. 3, depending on the mechanical properties of targets, typical impact features like individual depressions of sand grains, small flutes, and grooves might emerge on the original smooth surfaces. The maximum abrasion depth is about $4.0 \mathrm{~mm}$.
Fig. 3 Morphological change of the windward surface of sandstone block caused by the abrasion of aeolian sand grains

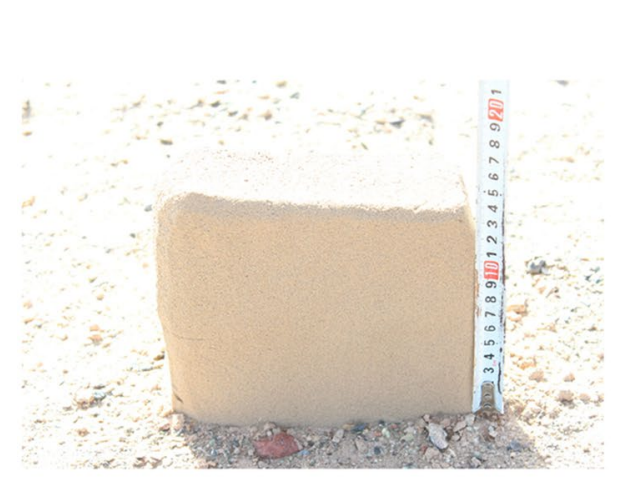

(a) the original surface is smooth.

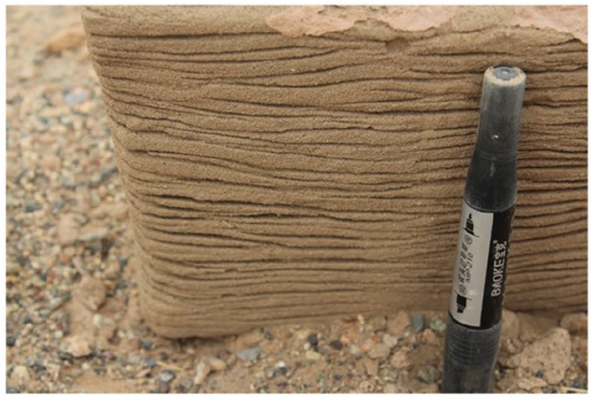

(c) small flutes emerge and the surface becomes severely rough.

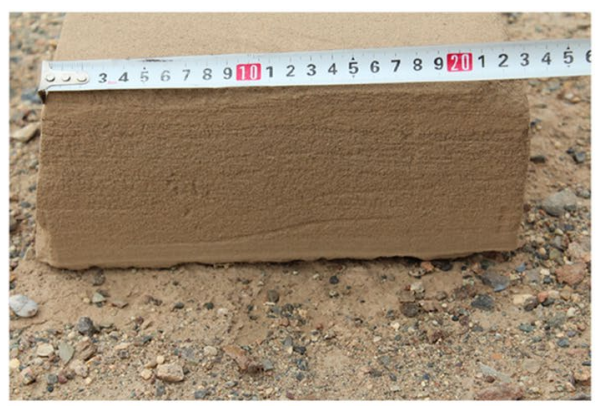

(b) individual depressions of impating grains appear and the surface becomes slightly rough.

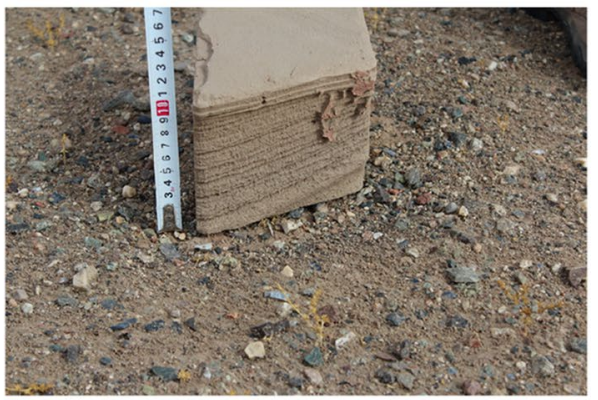

(d) grooves occur and abrasion depths are measurable. 


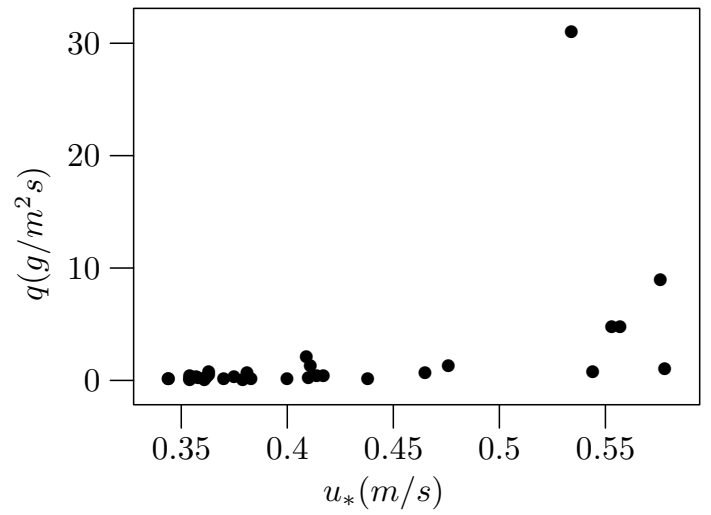

Fig. 4 Variation of the near-surface mass flux density $q$ with friction speed. The measured data of unsaturated mass flux density are too discrete to find a suitable polynomial function as done in the saturated aeolian sediment transport. Therefore, $q$ was fitted by a piecewise linear function of $u_{*}$

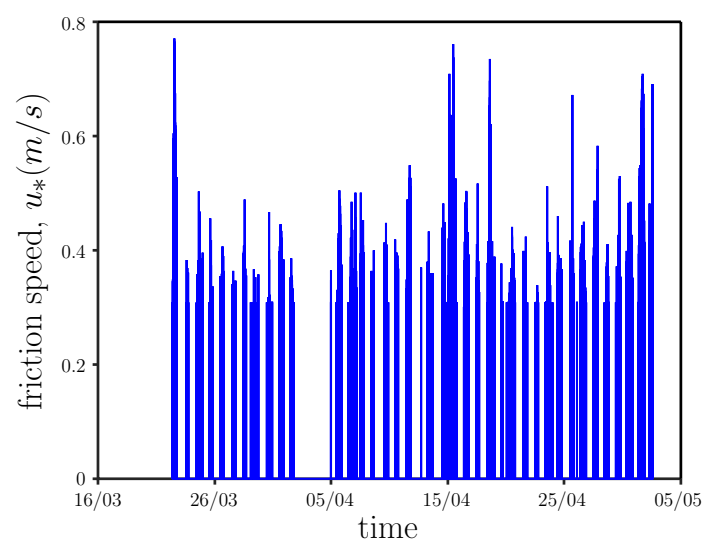

Fig. 5 Time series of wind erosion events during March 22-May 2

\subsection{Aeolian sediment transport and abrasion depths}

The variation of the mean mass flux density $q$ of the $0-10$ $\mathrm{cm}$ height with friction speed $u_{*}$ is plotted in Fig. 4. The saturated mass flux is the low-order polynomial function of $u_{*}$ [36]. But the data of unsaturated mass flux density are too discrete to find a suitable polynomial function. We choose a piecewise linear function of $u_{*}$ to fit $q$,

$q= \begin{cases}0 & \text { if } u_{*} \leq 0.30 \\ 0.0304 & \text { if } 0.30<u_{*} \leq 0.35 \\ 0.2149 & \text { if } 0.35<u_{*} \leq 0.40 \\ 0.6709 & \text { if } 0.40<u_{*} \leq 0.45 \\ 0.9254 & \text { if } 0.45<u_{*} \leq 0.50 \\ 8.4675 & \text { if } 0.50<u_{*} \leq 0.55 \\ q_{\max }=30.9378 & \text { if } u_{*}>0.55\end{cases}$

where the units of $q$ and $u_{*}$ are $\mathrm{g} / \mathrm{m}^{2} \mathrm{~s}$ and $\mathrm{m} / \mathrm{s}, q_{\max }$ is the maximum value of $q$ we obtained.

There are 2988 wind erosion events from March 22 to May 2, see Fig. 5 for the time series. They are discontinuously and almost uniformly distributed in the observation time. Some strong wind erosion events $\left(u_{*}>0.6 \mathrm{~m} / \mathrm{s}\right)$ intensively happen in the afternoons of March 22, April 18 and May 1. As shown in Fig. 6, the statistical characteristics of wind speed and duration indicate that most events occur when wind speed is slightly larger than threshold friction speed, and only last dozens of seconds. The accumulative effective abrasion duration is $36 \mathrm{~h}$. For the common rock or mineral components of vitrifaction in Table 1, the abrasion depths are calculated to be 0.101 $\mathrm{mm}, 0.214 \mathrm{~mm}, 0.381 \mathrm{~mm}, 0.134 \mathrm{~mm}, 0.010 \mathrm{~mm}$, and 1.619 $\mathrm{mm}$ respectively, when $C_{a}=3.00 \times 10^{9}$. Because the computed abrasion depth of soft sandstone $(1.619 \mathrm{~mm})$ is in
Fig. 6 The statistical characteristic of wind erosion events. Most events occur when wind speed is slightly larger than threshold friction speed, and last dozens of seconds

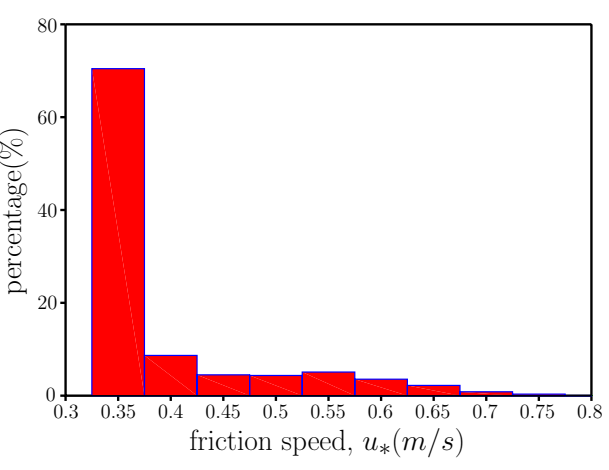

(a) friction speed

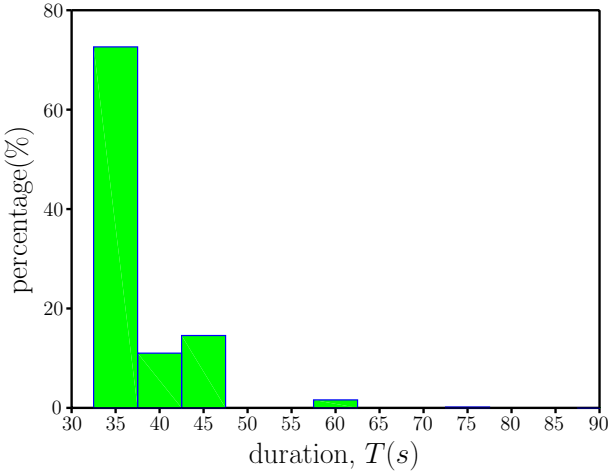

(b) duration 
the range of the in-situ values $(\leq 4.0 \mathrm{~mm}$ ) we measured, the expression of abrasion rate (7) is practicable.

In addition to determining abrasion rate and then describing the morphodynamic evolution process, physically-based models could provide some insights on dating the ventifacts composed of two or more minerals. Different from many previous studies, the short-term abrasion depths are tightly related with rock or mineral mechanical properties in the current model. It is difficult to determine the age of most ventifacts $[9,37]$, partly because their primary morphology is unknown. Since many ventifacts are heterogeneous, see Fig. A22 in Ref. [38] for a vivid example of quartz veins in a basalt rock-type ventifact, it is probable to estimate the time taken to form ventifacts by the different abrasion depths of rock components using (7), if local wind conditions are well understood.

\section{Conclusions}

In this study, an analytical expression for the abrasion rate of ventifact is derived, and then the abrasion coefficient is obtained from a previous wind tunnel experiment. The agreement of abrasion depth between theoretical prediction and field measurement indicates that the novel formula seems satisfactory. It is expected that the abrasion coefficient will be measured more accurately, and that such a physically-based model will be helpful for the studies on the morphodynamic evolution and chronology of ventifacts.

Acknowledgements We are grateful to Hui-Zhong Chen, Zong-Hu Hou, Chun-Lai Zhang, Feng Zhang, Xue-Yong Zou for assistance with the field measurements. The reviewer and editor offered insightful comments and suggestions for improving the quality of this manuscript.

Funding This research was supported by Natural Science Foundation of China projects (Nos. 41630747 and 41571006 ).

\section{Compliance with ethical standards}

Conflicts of interest The authors declare that there have no conflict of interest.

\section{References}

1. Knight J (2008) The environmental significance of ventifacts: a critical review. Earth Sci Rev 86(1-4):89

2. Laity JE (2009) Landforms, landscapes, and processes of aeolian erosion. In: Parsons AJ, Abrahams AD (eds) Geomorphology of desert environments. Springer, Dordrecht, pp 597-627
3. Durand M, Bourquin S (2013) Criteria for the identification of ventifacts in the geological record: a review and new insights. Comput Rendus Geosci 345(3):111

4. Laity JE (2011) Pavements and stone mantles. In: Thomas DSG (ed) Arid zone geomorphology. Wiley, Chichester, pp 181-207

5. Bridges NT, Greeley R, Haldemann AFC, Herkenhoff KE, Kraft M, Parker TJ, Ward AW (1999) Ventifacts at the Pathfinder landing site. J Geophys Res Planets 104(E4):8595

6. Greeley R, Bridges NT, Kuzmin RO, Laity JE (2002) Terrestrial analogs to wind-related features at the Viking and Pathfinder landing sites on Mars. J Geophys Res Planets 107(E1):5

7. Stout JE, Warren A, Gill TE (2009) Publication trends in aeolian research: an analysis of the bibliography of aeolian research. Geomorphology 105(1-2):6

8. Sharp RP (1949) Pleistocene ventifacts East of the Big Horn Mountains Wyoming. J Geol 57(2):175

9. Laity J, Bridges N (2013) Abraded systems. In: Treatise on geomorphology. Elsevier, pp 269-286

10. Laity J (2008) Deserts and desert environments. Deserts and desert environments. No. 2 in Environmental systems and global change series. Wiley-Blackwell, Chichester

11. Sharp RP (1964) Wind-driven sand in Coachella Valley, California. Geolog Soc Am Bull 75(9):785

12. Sharp RP (1980) Wind-driven sand in Coachella Valley, California: further data. Geolog Soc Am Bull 91(12):724

13. Spate AP, Burgess JS, Shevlin J (1995) Rates of rock surface lowering, Princess Elizabeth land, Eastern Antarctica. Earth Surf Process Landf 20(6):567

14. Mackay JR, Burn CR (2005) A long-term field study (19512003) of ventifacts formed by katabatic winds at Paulatuk, western Arctic coast. Canada. Can J Earth Sci 42(9):1615

15. Várkonyi PL, Laity JE (2012) Formation of surface features on ventifacts: modeling the role of sand grains rebounding within cavities. Geomorphology 139-140:220

16. Várkonyi PL, Laity JE, Domokos G (2016) Quantitative modeling of facet development in ventifacts by sand abrasion. Aeol Res 20:25

17. Kuenen PH (1960) Experimental abrasion 4: Eolian action. J Geol 68(4):427

18. Dietrich RV (1977) Impact abrasion of harder by softer materials. J Geol 85(2):242

19. Suzuki T, Takahashi K (1981) An experimental study of wind abrasion. J Geol 89(1):23

20. Greeley R, Leach RN, Williams SH, White BR, Pollack JB, Krinsley DH, Marshall JR (1982) Rate of wind abrasion on Mars. J Geophys Res 87(B12):10009

21. Scattergood RO, Routbort JL (1983) Velocity exponent in solidparticle erosion of silicon. J Am Ceram Soc 66(10):c184

22. Greeley R, Iversen JD (1985) Wind as a geological process: on Earth, Mars, Venus and Titan. Cambridge University Press, Cambridge

23. Lian-You L, Shang-Yu G, Pei-Jun S, Xiao-Yan L, Zhi-Bao D (2003) Wind tunnel measurements of adobe abrasion by blown sand: profile characteristics in relation to wind velocity and sand flux. J Arid Environ 53(3):351

24. Bridges NT, Laity JE, Greeley R, Phoreman J, Eddlemon EE (2004) Insights on rock abrasion and ventifact formation from laboratory and field analog studies with applications to Mars. Planet Space Sci 52(1-3):199

25. Laity JE, Bridges NT (2009) Ventifacts on Earth and Mars: analytical, field, and laboratory studies supporting sand abrasion and windward feature development. Geomorphology 105(3-4):202

26. Anderson RS (1986) Erosion profiles due to particles entrained by wind: application of an eolian sediment-transport model. Geol Soc Am Bull 97(10):1270 
27. Wang ZT, Wang HT, Niu QH, Dong ZB, Wang T (2011) Abrasion of yardangs. Phys Rev E 84(3):031304

28. Sunamura $T$ (2018) A fundamental equation for describing the rate of bedrock erosion by sediment-laden fluid flows in fluvial, coastal, and aeolian environments. Earth Surf Process Landf 43(15):3022

29. Cardarelli F (2008) Materials handbook: a concise desktop reference, 2nd edn. Springer, London

30. Shao Y (2008) Physics and modelling of wind erosion, 2nd edn. No. 37 in Atmospheric and oceanographic sciences library. Springer

31. Wang ZT, Zhang CL, Wang HT (2014) Intermittency of aeolian saltation. Eur Phys J E 37(12):126

32. Carneiro MV, Rasmussen KR, Herrmann HJ (2015) Bursts in discontinuous Aeolian saltation. Sci Rep 5(1):11109

33. Sherman DJ, Li B, Ellis JT, Swann C (2018) Intermittent aeolian saltation: a protocol for quantification. Geogr Rev 108(2):296

34. Bridges N, Laity J (2013) Fundamentals of aeolian sediment transport: Aeolian abrasion. In: Treatise on Geomorphology. Elsevier, pp 134-148
35. Butterfield GR (1999) Near-bed mass flux profiles in aeolian sand transport: high-resolution measurements in a wind tunnel. Earth Surf Process Landf 24(5):393

36. Wang ZT, Zhang CL, Cen SB (2018) Unsteady aeolian saltation. Eur Phys J E 41(10):121

37. Knight J (2019) Wind erosion. In: Livingstone I, Warren A (eds) Aeolian geomorphology: a new introduction. Wiley-Blackwell, Hoboken, pp 63-68

38. Bourke MC, Viles HA (2017) Aeolian Features. In: A photographic atlas of rock breakdown features in geomorphic environments. Planetary Science Institute, pp 6-22

Publisher's Note Springer Nature remains neutral with regard to jurisdictional claims in published maps and institutional affiliations. 